\title{
Characterization of Magnetoelectropolished Stainless Steel Surfaces' Texture by Using the Angle-Resolved Scattering and Image Processing Analysis Methods
}

\author{
Wojciech Kapłonek $^{1}$ (D), Krzysztof Rokosz ${ }^{2, *}$ ad and Danil Yurievich Pimenov ${ }^{3}$ (D) \\ 1 Department of Production Engineering, Faculty of Mechanical Engineering, Koszalin University of \\ Technology, Racławicka 15-17, 75-620 Koszalin, Poland; wojciech.kaplonek@tu.koszalin.pl \\ 2 Department of Engineering and Informatics Systems, Faculty of Mechanical Engineering, Koszalin \\ University of Technology, Racławicka 15-17, 75-620 Koszalin, Poland \\ 3 Department of Automated Mechanical Engineering, South Ural State University, Lenin Prosp. 76, \\ 454080 Chelyabinsk, Russia; danil_u@rambler.ru \\ * Correspondence: rokosz@tu.koszalin.pl; Tel.: +48-943478354
}

Received: 21 July 2020; Accepted: 11 August 2020; Published: 13 August 2020

\begin{abstract}
In this article, the results of preliminary experimental studies related to a fast, non-contact assessment of the AISI 316L stainless austenitic steel surfaces after electrochemical polishing in a magnetic field have been presented. The experiments were realized with the use of a modified angle-resolved scattering (ARS) method based on the analysis of angular distribution of the scattered light intensity. Digital images of such distribution were acquired for selected areas of examined samples-base surface and surface after magnetoelectropolishing (MEP) process. Parametric analysis oriented toward the calculation of selected key geo- and photometric parameters carried out in Image Pro ${ }^{\circledR}$-Plus software allowed for characterization of the surface conditions of the assessed samples in terms of their scattering properties. The obtained experimental results confirmed the usefulness of the ARS method used in the presented studies as well as the possibility of its practical use (after appropriate modifications) on a wider scale, especially in industrial applications.
\end{abstract}

Keywords: magnetoelectropolishing; stainless steel; non-contact methods; angle-resolved scattering; image processing and analysis

\section{Introduction}

At the beginning of the twentieth century, the production of austenitic stainless steels for application in the chemical, energy and food industries was introduced. The continuation of the research in the early 1970s allowed for the improvement of the existing methods thanks to the application of new refining and casting processes. It has to be pointed out that the addition of nickel (8-23\%) and/or copper $(0.2-0.75 \%)$ and/or manganese $(0.3-4 \%)$ is necessary to obtain the austenite structure. Other elements, such as carbon $(0.02-0.08 \%)$, chromium $(17-28 \%)$, molybdenum $(2-8 \%)$ and nitrogen $(0.1-0.6 \%)$, have a significant influence on both the mechanical properties and the corrosion resistance. The yield (170-500 MPa) and tensile (214-795 MPa) strengths are obtained mainly by addition of carbon and nitrogen [1]. In addition, they cannot be hardened by heat treatment, so they are cold-worked by forming, spinning and swaging, which increase their strength. Electrochemical polishing processes are used to reduce the surface roughness as well as to form on the top of surface the chromium enriched nano-layer, which has better corrosion resistance than the air-oxidized matrix [2,3]. 
The first mentions of electrochemical polishing (EP) date back to 1912, when the German government issued a patent for silver finishing [4]. The next milestone was Jacquet's work on polishing copper in phosphoric acid $\mathrm{H}_{3} \mathrm{PO}_{4}$ [5], followed by the work of, among others, Elmore [6], Wagner [7], Hoar [8] and Hensel [9]. The subsequent studies by Landolt showed that the double layer consists of three sublayers: the first is a semiconductor type with a metal surface $10-11 \mathrm{~nm}$ thick, the second is a discontinuous layer of metal ions subject to digestion, and the third is a diffusion layer much thicker than the previous two [10]. The proposal of a discontinuous layer of metal ions is a good solution; however, it should be considered that this liquid layer may also contain anions derived from the electrolyte or complexes containing water molecules, which the author of the article does not analyze. Kirchheim et al. [11] considered the change in current density with time on the basis of Fick's second law, distinguishing three phases of EP. They noticed that, in the first phase of the process, the current density is approximately constant over time; then, in the second phase, it decreases, which may be due to the formation of a permanent film of reaction products on the anode; it then reaches a constant level again due to natural or forced convection in the case of long-term polishing and/or mixing the solution. The presented theory assumes the mass transport mechanism in the layer in all three phases of EP diffusion. An analysis of the literature shows that, in the EP process at the metal-solution interface, complex processes take place, the explanation of which may be based on various models. The models have a common feature-the division into layers, the outer ones being more enriched with ions from the solution, and the inner ones with cations of the metals of the base. The concept of Grimm et al. [12] was based on three layers: the internal compact salt oxide enriched with alloy metal cations (substrate), which turns into a porous/semi-liquid composed of hydrated salts, complexes with a negative total charge and anions derived from the electrolyte and external diffusion.

Currently, research on the process of standard EP $[13,14]$ is still being carried out, an example of which is a better description of the treated surfaces in terms of chemical composition [15,16], hydration of the top layer [17] and surface roughness [18,19], corrosion resistance [20,21] as well as reduced Young's modulus and nanohardness [22]. The latest research concerns magnetoleltoctopolishing (MEP) [15-17] and polishing with the use of very high densities $\left(1000 \mathrm{~A} / \mathrm{dm}^{2}\right)[23,24]$.

The effectiveness and correctness of the EP and other polishing processes can be verified using a number of advanced observation measurement methods, presented, among others, by Pahk et al. [25], Duparré [26] as well as Rebeggiani and Rosén [27]. Since the obtained surface is smooth, with small heights of surface irregularities, and additionally is characterized by a low resistance to pollution, susceptible to deformation and sensitive to physical or chemical effects, the use of non-contact methods is most advantageous in this case. These include high-accuracy variations of microinterference methods (e.g., phase shifting interferometry (PSI)), advanced optical microscopy (e.g., confocal laser scanning microscopy (CLSM), focus variation microscopy (FVM)) and high-resolution electron microscopy (e.g., scanning electron microscopy (SEM)) as well as scanning probe microscopy (e.g., atomic force microscopy (AFM)). An interesting group of such methods are also those which are based on the imaging and analysis of scattered light. The characteristics of the abovementioned methods in relation to their resolution (vertical and lateral) and observation measurement ranges are presented schematically in Figure 1. 


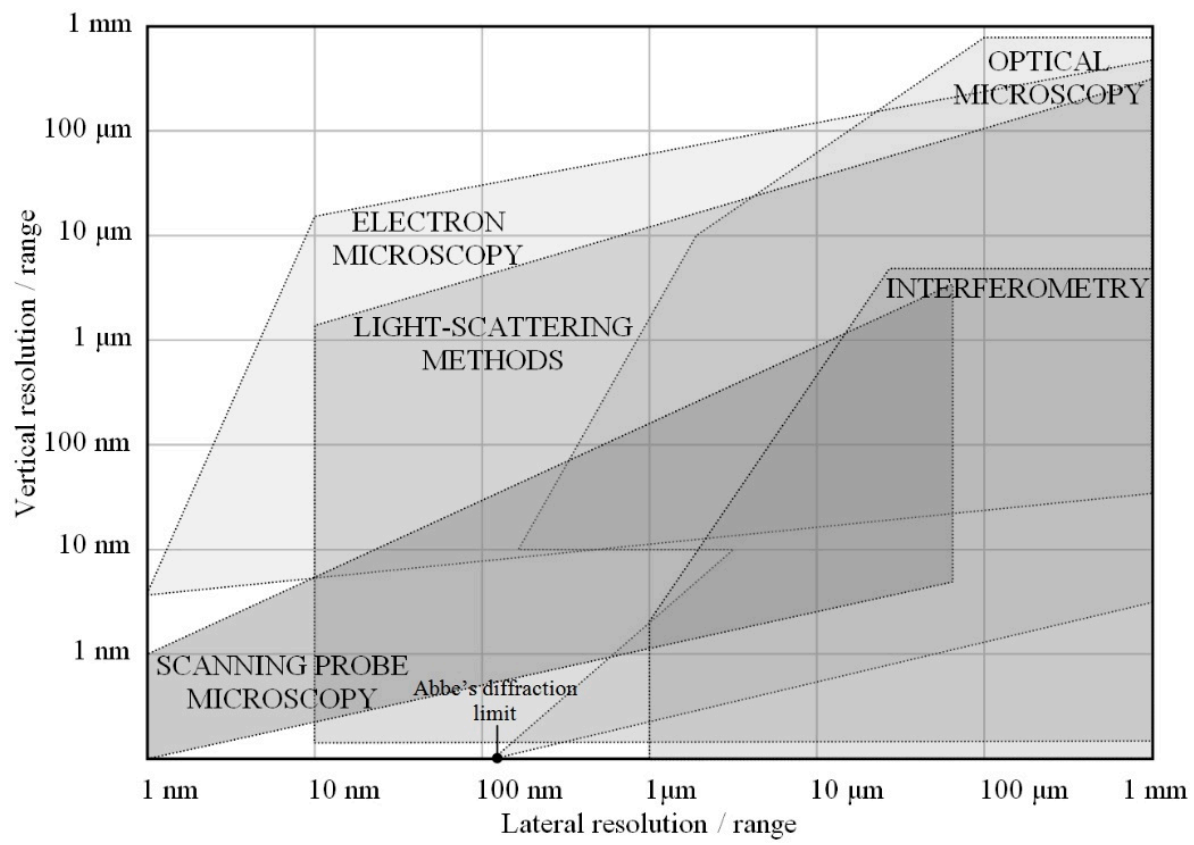

Figure 1. Approximate resolution ranges (horizontal and lateral) characterizing the modern advanced observation measuring non-contact methods used for assessment of surfaces after the polishing processes, modified based on [28].

One of the light-scattering methods is angle-resolved scattering (ARS), widely presented by Azarova at al. [29], Bloomstein et al. [30], Schröder et al. [31], Zhenrong et al. [32] as well as Kapłonek and Nadolny [33]. This method uses the measurement of the angular distribution of scattered light intensity. Its theoretical basis was formulated in 1967 by Torrance and Sparrow [34]. In TorranceSparrow (T-S) theory, as a model of scattering surface, a mirror facet model (MFM) is used. The ARS method comes in many variants and varieties, which allows for flexible selection of resolution and measuring range for a given application. Due to the relatively wide range of resolutions offered, the ARS method is basically used in applications, in which the measured surfaces are characterized by the following:

- relatively low heights of irregularities from approx. 0.2 to $200-300 \mathrm{~nm}$ (optical and opto-electronical elements, silicon wafers, tooth implants and artificial hip joint prosthesis stem balls),

- high heights of irregularities from approx. 500 to 1500-2000 nm (precisely machined machine parts, automotive components, medical devices elements and parts of aeronautical engines).

The assessment of the surface texture after the EP and other polishing processes requires the application of the first of the mentioned varieties of the ARS, as reported Łukianowicz [35].

In the classical approach, the assessment of polished surfaces based on the ARS method boiled down to calculating the values of the parameters defining the angular distribution of scattered light intensity, considered in relation to the selected plane or in space. In the first case, usually the scattering angle $\theta_{d}$ was used, whose graphic form was the curve of the angular distribution of scattered light intensity. In the second case, the function was used, which was the ratio of the scattered surface radiance $L e$ (determined within the solid angle $d \Omega$ ) to the incident surface irradiance. This important function, defined in 1970 by Nikodemus [36], is known under the acronym BRDF (bidirectional reflectance distribution function) or BSDF (bidirectional scatter distribution function). Its general form is expressed by dependence (1):

$$
B R D F=\frac{L_{e} d \Phi_{e} / d \Omega}{\Phi_{e i} / A \Phi_{e i} \cos \theta_{d}}=\frac{16 \pi^{2}}{\lambda^{4}} \cos \left(\theta_{i}\right) \cos \left(\theta_{d}\right) Q S\left(f_{x}, f_{y}\right)
$$


where

$$
L_{e}=\frac{d \Phi_{e}}{A d \Omega \cos \theta_{d}}
$$

and where $L_{e}$-scatter surface radiance, $A$-illuminated surface area, $d \Phi_{e}$ 一the radiant flux/power scattered within the solid angle, $d \Omega$-solid angle, $\Phi_{e i}$ - the radiant flux/power incident of surface, $\lambda$-wavelength of light, $\theta_{i}$-angle of incidence, $\theta_{d}$ —scattering angle, $Q$-non-dimensional factor depending on the azimuthal scattering angle $\phi$, also allowing for the polarization state of incident light and the optical properties of the reflecting surface, $S(f x, f y)$-two-dimensional surface power spectral density function, $f x$, $f y$-spatial frequencies of the surface roughness.

With the dynamic development of modern computer programming techniques, and particularly of new methods and algorithms of computer image processing and analysis, the assessment of the angular distribution of scattered light intensity became possible also from its acquired digital image, as presented by Shen et al. [37], Espinosa-Luna et al. [38], Kapłonek et al. [39], Jošt et al. [40] as well as Kapłonek and Nadolny [41]. The image can be still, as shown by Shen et al. [37], Rao and Raj [42] as well as Kapłonek et al. [43], or it can be also a set of moving images in the form of video sequences-this case was discussed by Kapłonek and Łukianowicz [44]. Regardless of the form, the acquired digital image of scattered light carries important information about the condition of the assessed surface. This information, if properly transformed (specialized computer software) into the values of selected geometrical and photometric parameters, can be correlated with selected surface texture parameters.

In this article, the modified ARS method supported by the image processing and analysis techniques for assessment of surfaces after the MEP process has been presented and discussed. Information covering the characteristics of the used samples, MEP process and acquisition of digital images of the angular distribution of scattered light intensity is given in Section 2, whereas the obtained experimental results with proper interpretation are presented and discussed in Section 3. At the end of the article, a summary with the most important conclusions resulting from the experimental studies carried out are formulated and given, as well as guidelines for future work.

\section{Methodology of Experimental Studies}

\subsection{Characteristics of the Samples}

For experimental studies, we used AISI 316L stainless austenitic steel samples, which were prepared in the form of rectangular and square plates of dimensions $30 \times 5 \mathrm{~mm}$ (10 samples) and $30 \times 30 \mathrm{~mm}$ (10 samples), cut from the 1-mm metal sheet. The chemical composition of the used material with its selected physical properties are given in Table 1.

Table 1. Chemical composition and physical properties of AISI 316L stainless austenitic steel.

\begin{tabular}{|c|c|c|c|c|c|c|c|c|c|c|c|c|c|}
\hline \multicolumn{14}{|c|}{ Content of the Elements, wt $\%$} \\
\hline $\mathrm{Cr}$ & $\mathrm{Ni}$ & Mo & $\mathrm{Mg}$ & $\mathrm{Si}$ & $\mathrm{Cu}$ & $\mathrm{V}$ & Co & $\mathrm{C}$ & $\mathrm{Ti}$ & $\mathrm{P}$ & $\mathrm{S}$ & $\mathrm{N}$ & $\mathrm{Fe}$ \\
\hline 17.07 & 10.26 & 1.9 & 1.68 & 0.64 & 0.19 & 0.11 & 0.04 & 0.03 & 0.03 & 0.02 & 0.04 & 0.04 & balance \\
\hline \multicolumn{14}{|c|}{ Physical Properties } \\
\hline \multicolumn{3}{|c|}{ Density } & \multicolumn{2}{|c|}{ Hardness } & \multicolumn{3}{|c|}{ Specific heat } & \multicolumn{4}{|c|}{ Thermal conductivity ${ }^{(1)}$} & \multicolumn{2}{|c|}{ Melting range } \\
\hline \multicolumn{3}{|c|}{$7.90 \mathrm{~g} / \mathrm{cm}^{3}$} & \multicolumn{2}{|c|}{ max. $215 \mathrm{HB}$} & \multicolumn{3}{|c|}{$450 \mathrm{~J} /(\mathrm{kg} \cdot \mathrm{K})^{(2)}$} & \multicolumn{4}{|c|}{$14.6 \mathrm{~W} /(\mathrm{m} \cdot \mathrm{K})$} & \multicolumn{2}{|c|}{$1390-1440{ }^{\circ} \mathrm{C}$} \\
\hline \multicolumn{3}{|c|}{ Yield strength } & \multicolumn{2}{|c|}{ Tensile strength } & \multicolumn{3}{|c|}{ Elongation at break } & \multicolumn{4}{|c|}{ Modulus of elasticity } & \multicolumn{2}{|c|}{ Electrical resistivity } \\
\hline \multicolumn{2}{|c|}{$220 \mathrm{MPa}$} & & \multicolumn{2}{|c|}{$520-680 \mathrm{MPa}$} & \multicolumn{3}{|c|}{$55 \%$} & \multicolumn{4}{|c|}{$193 \mathrm{GPa}$} & \multicolumn{2}{|c|}{$74 \mu \Omega \cdot \mathrm{cm}^{(3)}$} \\
\hline
\end{tabular}

The MEP process was performed with use of DC power supply in a magnetic field of $66 \mathrm{mT}$ and two current densities, i.e., $800 \mathrm{~A} / \mathrm{dm}^{2}$ (MEP-800) and $50 \mathrm{~A} / \mathrm{dm}^{2}$ (MEP-50). For the experimental studies, a proprietary sulfuric $\left(\mathrm{H}_{2} \mathrm{SO}_{4}, 95 \%, 98.08 \mathrm{~g} / \mathrm{mol}\right) /$ orthophosphoric $\left(\mathrm{H}_{3} \mathrm{PO}_{4}, 85 \%, 98 \mathrm{~g} / \mathrm{mol}\right)$ ( $40-60 \%$ by vol.) acid mixture of electrolytes without additional water was used. To eliminate any 
possible changes in the electrolyte composition due to increased temperatures, no water was used for the electrolyte in the study. For each run, the electrochemical cell, made of glass, contained around $500 \mathrm{~cm}^{3}$ of electrolyte.

\subsection{Acquisition of Digital Images of the Angular Distribution of Scattered Light Intensity}

For acquisition of digital images of the angular distribution of scattered light intensity, the experimental setup was prepared. Its general scheme is presented in Figure 2a.

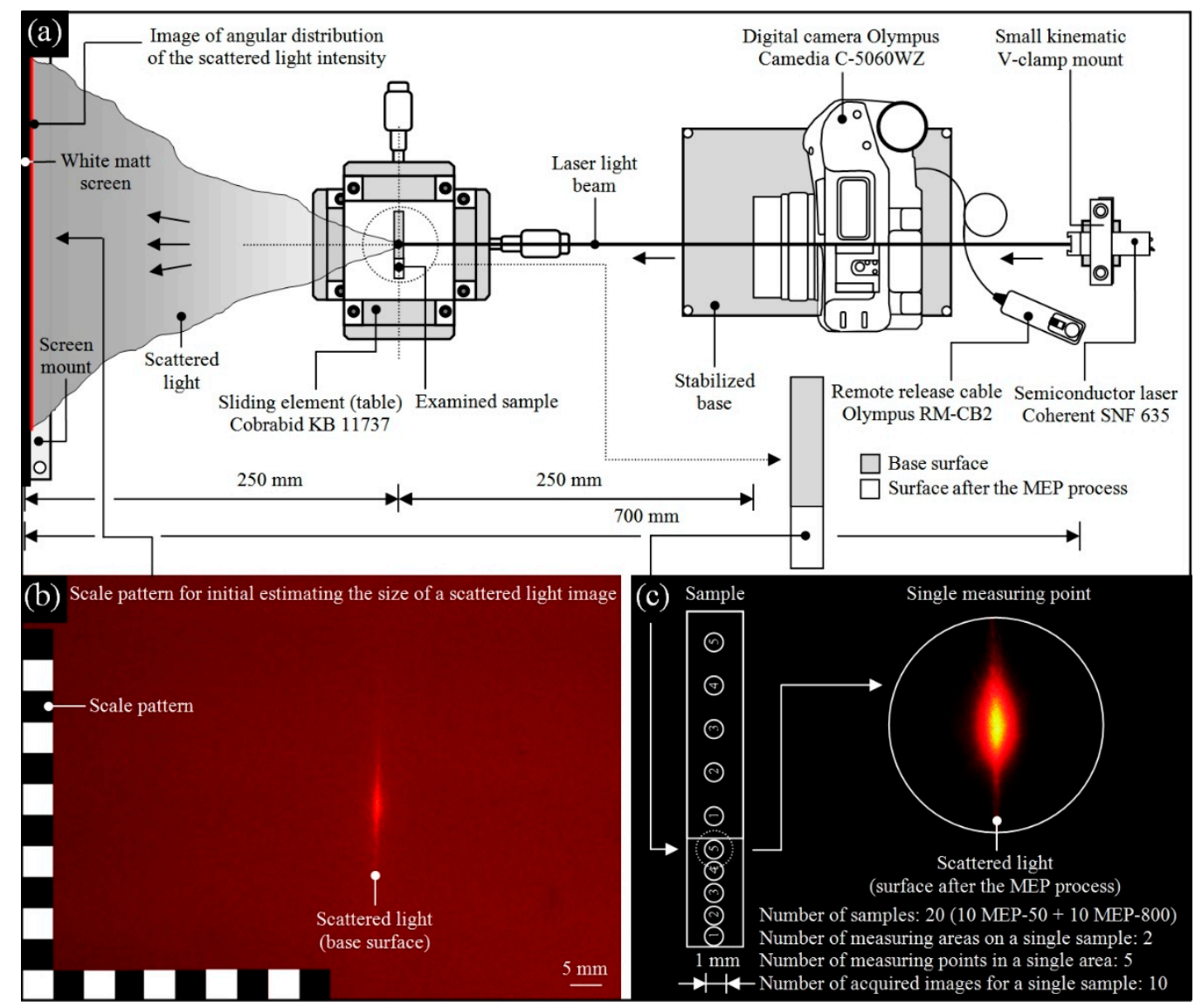

Figure 2. Graphical scheme presenting the experimental setup used for acquisition of digital images of the angular distribution of scattered light intensity: (a) general view with key components and the distances between them; (b) scale pattern used for initial estimating of scattered light image size; (c) methodology of acquisition of scattered light image and main assumptions of acquisition process.

The analyzed samples were placed on an $x-y$ stage constructed from two horizontal movement mechanisms, type KB 11,737 (Cobrabid, Warsaw, Poland). The mechanisms provided precise sample movement in the range of 0 to $25 \mathrm{~mm}$, with a positioning accuracy of $0.01 \mathrm{~mm}$. As the radiation source, a semiconductor laser, Lasiris ${ }^{\mathrm{TM}}$ SNF 635 (Coherent Inc., Santa Clara, CA, USA), which emitted a continuous light beam from the visible spectrum range with wavelength $\lambda=635 \mathrm{~nm}$, was used. The beam was directed at an angle of incidence of $50^{\circ}$ and illuminated the examined surface of the sample. The reflected and partially scattered light from the examined surface created an optical image of scattered light visible in the observation plane. As an observation plane, a $300 \mathrm{~mm} \times 300 \mathrm{~mm}$ white matt screen with scale pattern used for initial estimating of scattered light image size was used. The creation of optical images of scattered light on the observation plane is presented in Figure $2 \mathrm{~b}$.

For its acquisition, a digital camera, Camedia C-5060WZ by Olympus, which was equipped with a $4 \times$ wide angle zoom lens $5.7-22.9 \mathrm{~mm}$, was used. The camera was equipped with a matrix photoelectric 
detector of CCD type, sized 1/1.8" with an effective number of 5.10 million pixels. The same acquisition parameters were used for all samples: exposure time $t_{\exp }=1 \mathrm{~s}$, lens stop value F4.0, auto white balance, image resolution $2592 \times 1944$ pixels, ISO sensitivity 200, saving format *.jpg and HQ image quality. The camera was placed on a support stand and directed towards the observation plane. All distances from the abovementioned elements are presented in Figure 2a.

The acquisition process was realized identically for all of the examined samples. Its methodology and main assumptions are presented in Figure 2c. Ten points were designated on their surface (fivesurface after the MEP process, five-base surface), for those the scattered light images were acquired. The dimension of measurement single point was $1 \mathrm{~mm}$. Total number of acquired images from a single sample was ten.

\subsection{Characteristics of Image Processing and Analysis Process}

All the acquired digital images of the angular distribution of scattered light intensity were subjected to computer analysis. Before this, the images were appropriately pre-processed (horizontal levelling, cropping, tonal correction) and binarized in automatic mode (iteration: 1, count: 1, threshold levels: in the range 7.45-9.80\% for MEP surface and in the range 15.68-19.60\% for base surface). All the above procedures were carried out using ImageJ 1.57 (W. Rasband, NIH, LOCI, University of Wisconsin, Madison, WI, USA). This popular Java-based image processing and analysis software was widely characterized by Abràmoff et al. [45], Schneider et al. [46] and Rueden et al. [47]. The prepared images were subjected to parametric analysis in Image Pro ${ }^{\circledR}$-Plus 5.1 (Media Cybernetics Inc., Rockville, MD, USA) software. More information about this extensive program environment dedicated to advanced image processing and analysis was given by Fritzsch et al. [48] and Dongming [49], whereas an in-depth comparison of these software programs is presented Ye et al. [50]. The methodology of image processing and analysis used during the experimental studies is in general form schematically presented in Figure 3.

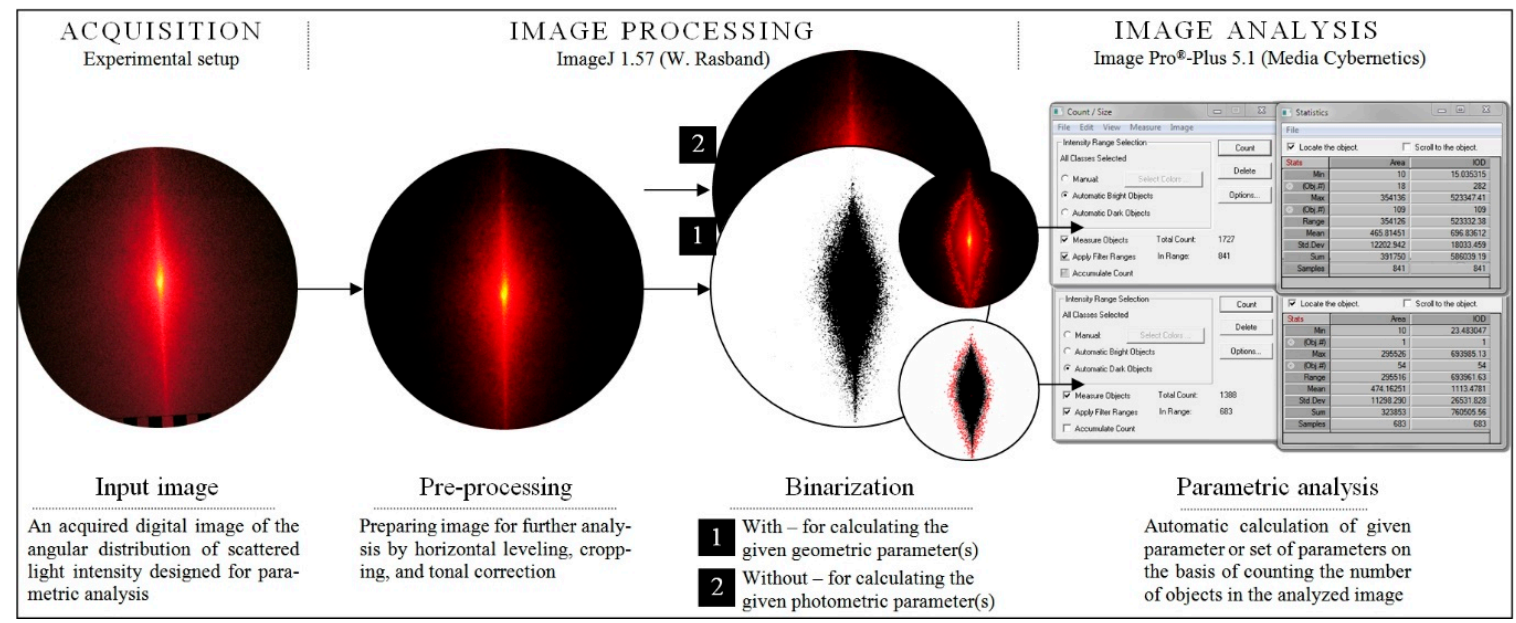

Figure 3. Methodology of processing and analysis process carried out for digital images of the angular distribution of scattered light intensity using Image 1.57 and Pro ${ }^{\circledR}$-Plus 5.1 software.

The main goal of the conducted analysis was to determine values of the key parameters which can be useful in characterizing these types of images. For this purpose, the selected functions available in Image-Pro ${ }^{\circledR}$ Plus 5.1 software were used. The function Count/Size, an example window of which is presented on the right side in Figure 3, was realized in two steps. Step I involved counting all elements in the analyzed image in automatic mode, giving values of total counts and counts in the range. Each counted object in an image was labeled using red cross. In step II, the software calculated the values of selected geo- and photometric parameters (from more than 50 available) with statistical 
summary. An example window of the Statistics function is presented on the right side in Figure 3. This summary included selected statistical values (minimum (min.), maximum (max.), average (mean), standard deviation (std. dev.) and accumulated (sum)) calculated for the declared parameters.

In general, interesting parameters which may be relevant in the analysis of images of the angular distribution of scattered light intensity are those representing geo- and photometric groups. Since the authors used the Image-Pro ${ }^{\circledR}$ Plus environment, they chose one key parameter each from the groups available in this software. As a key geometric parameter, the area (of the bright regions of an image of scattered light) $A n$ was proposed. The values of $A n$ can be calculated from dependence (3), given below:

$$
A n=\sum_{i=0}^{N-1} \sum_{j=0}^{N-1} I(i, j)
$$

where $i, j$-coordinates of the corresponding image elements ( $i$-row number, $j$-column number), $I(i, j)$ - grey scale intensity.

From the group of photometric parameters, the integrated optical density (of the bright regions of an image of scattered light) $I_{\Sigma}$ was proposed. In this case, values of $I_{\Sigma}$ can be calculated from dependence (4), given below:

$$
I_{\Sigma}=\sum_{i, j \in A n} I(i, j)
$$

where $i, j$-coordinates of the corresponding image elements ( $i$-row number, $j$-column number), $I(i, j)$ - grey scale intensity, $A n$-image area.

The values of the above parameters were obtained using the Count/Size function, whereby for $A n$, the values were calculated for images after binarization (all the dark objects were counted), and for $I_{\Sigma}$ from input images without binarization (all the bright objects were counted).

\section{Results and Discussion}

In this section, selected results of acquisition and analysis of images of the angular distribution of scattered light intensity are presented and discussed. The acquisition process realized using the experimental setup (described in Section 2.2) allowed us to obtain a set of scattered light images. Examples of images acquired for two different types of samples (MEP-800 and MEP-50) are presented in Figure 4.

The polished surface after the MEP process is characterized by relatively high anisotropy. This means that, regardless of the direction of incidence of the laser beam, the angular distribution of the scattered light intensity should take the same form. Typically, the distribution of the scattered light intensity of such a surface is situated on a straight line segment, being the intersection of the incidence plane and observation plane. The resulting image is thus close to a point and takes the form of a circle (Figure $4 \mathrm{a}$ ) or an ellipse (Figure $4 \mathrm{~b}$ ). In some cases, the above forms can be visually supplemented with additional angular distribution(s) of scattered light intensity resulting from the occurrence of various types of defects on the analyzed surface. These defects, defined by the EN-ISO 8785:1999 standard [51] and appearing under the acronym SIM (surface imperfections), in this case occurred on both surfaces shown in Figure 4 in the form of scratches. 

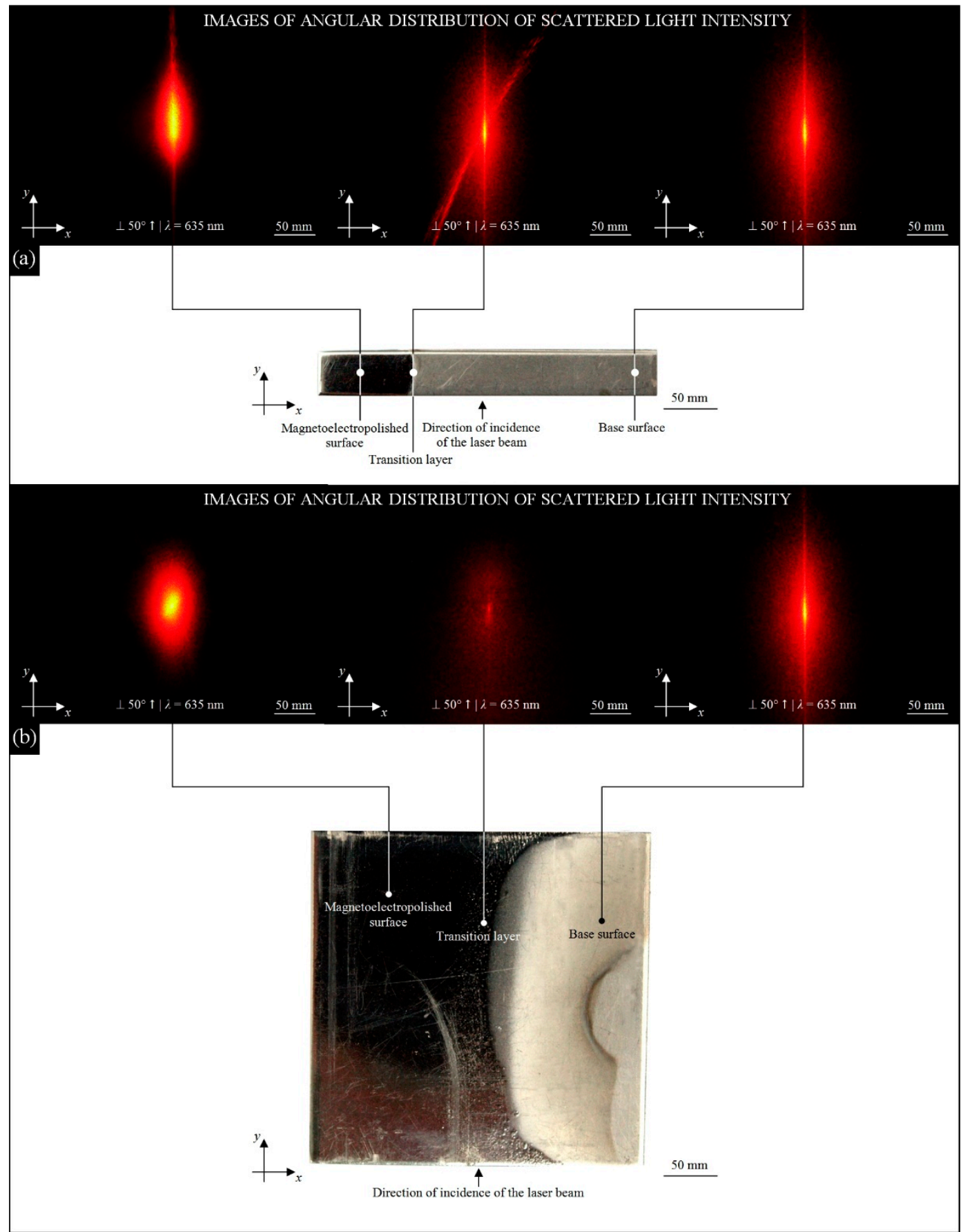

Figure 4. Collection of example results of acquisition of digital images of the angular distribution of scattered light intensity carried out for surface after the MEP process, transition layer and base surface occurring on sample: (a) MEP-800; (b) MEP-50.

The results of image analysis in the form of the calculated values of the area (of the bright regions of scattered light image) and integrated optical density (of the bright regions of scattered light image) parameters are presented in Figures 5 and 6, respectively.

In Figure $5 a, b$, bar graphs presenting calculated values of the area (of the bright regions of scattered light image) for all analyzed MEP-800 and MEP-50 samples are shown. The light gray bar is a value calculated for the surface after the MEP, whereas the dark gray bar is a value calculated for the base surface. The red dotted line represents an average value. These values obtained for both 
types of the samples were at the same level. For the MEP-800 samples (Figure 5a), the following mean values were obtained: $A n_{\text {avr }}=603.965 \mathrm{~mm}^{2}$, $\min . A n_{\text {avr }}=551.596 \mathrm{~mm}^{2}$ (MEP-800-7) and max. $A n_{\text {avr }}=551.596 \mathrm{~mm}^{2}$ (MEP-800-6). Meanwhile, for the MEP-50 samples (Figure 5b), the following mean values were obtained: $A n_{\text {avr }}=664.191 \mathrm{~mm}^{2}$, min. $A n_{\text {avr }}=514.952 \mathrm{~mm}^{2}(\mathrm{MEP}-50-6)$ and max. $A n_{\text {avr }}=811.716 \mathrm{~mm}^{2}$ (MEP-50-2). The surface after the MEP was characterized by $49 \%$ (MEP-800) and over $49 \%$ (MEP-50) lower An values than the base surface. Additionally, the MEP surface showed much better reflection properties than the base surface. The created image of the angular distribution of scattered light intensity was close to a circle - typical for polished surfaces with small heights of surface irregularities. A similar situation was observed for values of the photometric parameter of integrated optical density (of the bright regions of scattered light image), presented in Figure 6a,b, respectively. For the MEP-800 samples (Figure $6 a$ ), the following mean values were obtained: $I_{\text {Iavr }}=363,442.542$ a.u.,

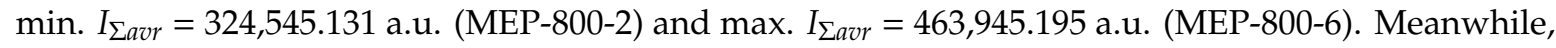
for the MEP-50 samples (Figure 6 b), the following mean values were obtained: $I_{\text {Lavr }}=388,694.281$ a.u., min. $I_{\Sigma a v r}=302,339.5$ a.u. (MEP-50-6) and max. $I_{\Sigma a v r}=500,471.31$ a.u. (MEP-50-2). The surface after the MEP was characterized by $51 \%$ (MEP-800) and $54 \%$ (MEP-50) lower $I_{\Sigma}$ values than the base surface. These values confirmed the earlier trend of $A n$ values and also closely corresponded to the visually analyzed images of the angular distribution of scattered light intensity.

(a)

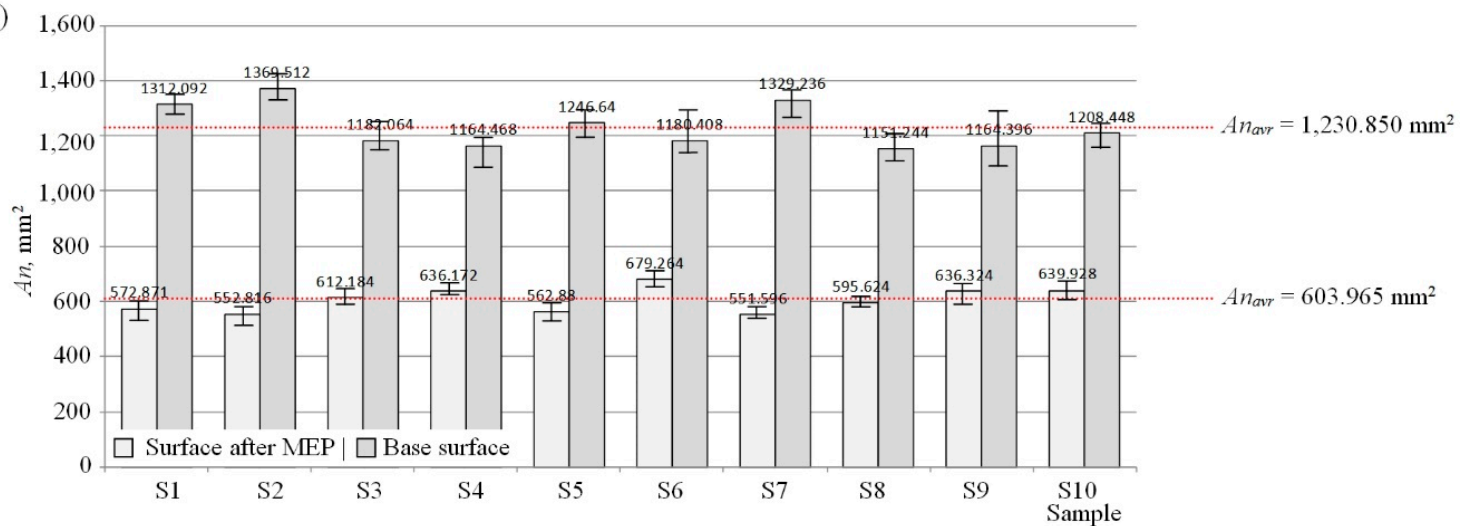

(b)

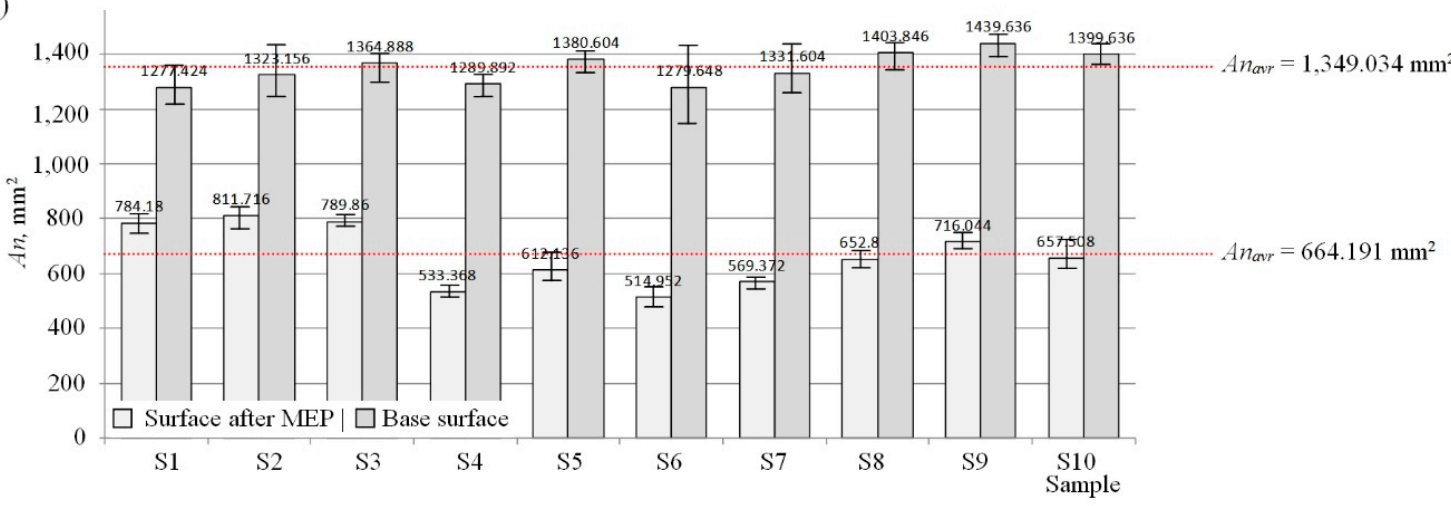

Figure 5. Average values of area (of the bright regions of scattered light image) obtained for surface after the MEP process and base surface for samples (a) MEP-800; (b) MEP-50. 
(a)
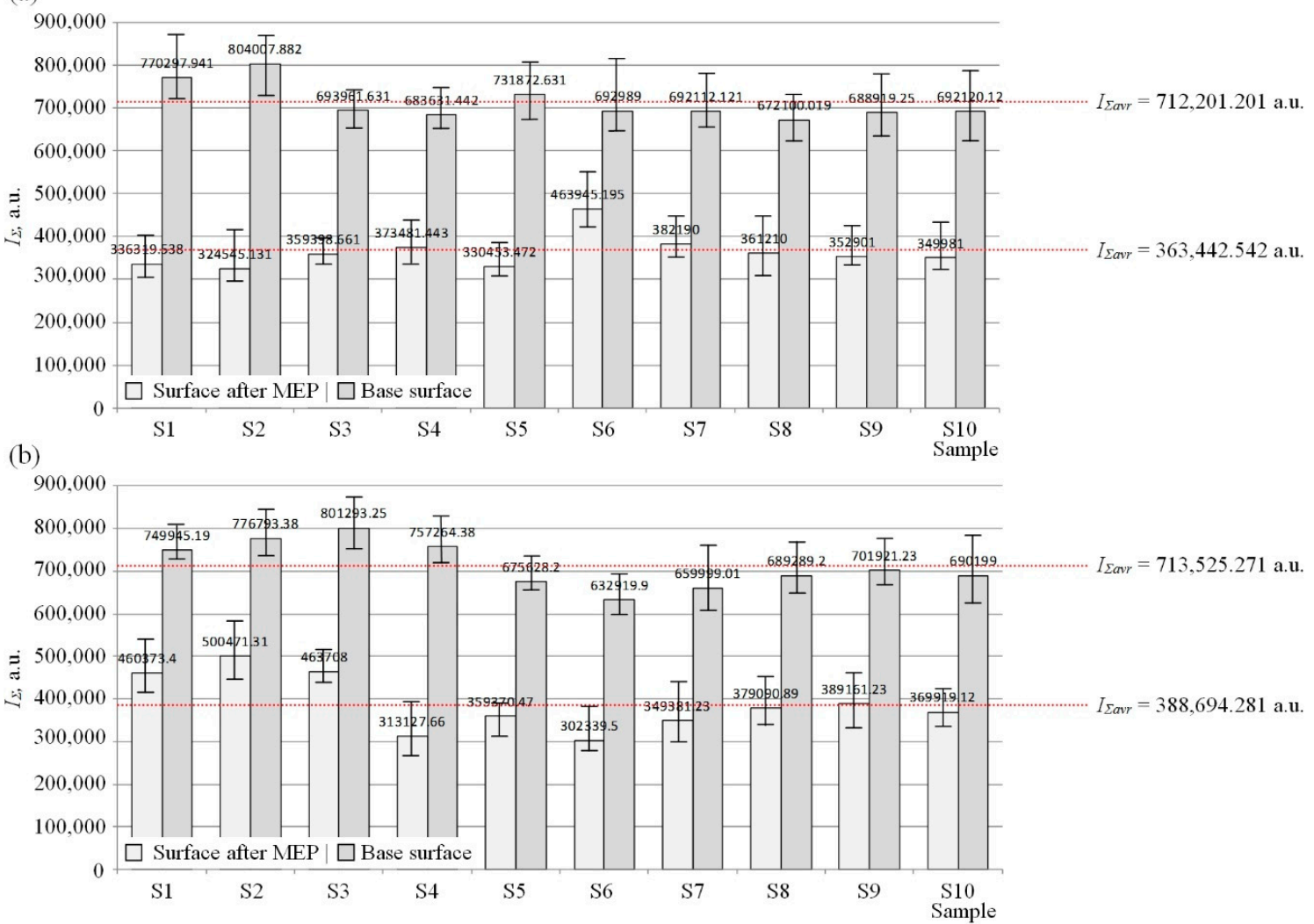

Figure 6. Average values of integrated optical density (of the bright regions of scattered light image) obtained for surface after the MEP process and base surface for samples (a) MEP-800; (b) MEP-50.

For the conducted comparative analysis of the obtained results, a setting of the values obtained during the previously conducted experimental studies was prepared. To facilitate comparison, two surfaces made of AISI 316L stainless austenitic steel after the electrochemical polishing (EP, MEP), as well as four surfaces made of gray cast iron GJL 150, brass CW 612N, aluminum alloy AW-6082 and carbon steel C45 after the conventional machine polishing (CMP; realized by using abrasive sheets and $\mathrm{Al}_{2} \mathrm{O}_{3}$-based polishing paste), were selected. For all the samples compared, digital images of the angular distribution of scattered light intensity were acquired and the average values of areas (of the bright regions of scattered light image) were calculated. These values were correlated with the basic roughness (profile) parameter-the roughness average $R a$. The used experimental setup allowed us to measure this in a range from $\sim 0.02$ to $\sim 1 \mu \mathrm{m}$. Additionally, the $R a$ values were measured also by using an optical profilometer Talysurf CLI 2000 (Taylor-Hobson, Leicester, Great Britain) equipped with a laser triangulation sensor LK-031 (Keyence Corp., Osaka, Japan). This configuration allowed us to conduct surface roughness measurements in a range up to $10 \mathrm{~mm}$ at resolutions of $1 \mu \mathrm{m}$ (vertical) and $30 \mu \mathrm{m}$ (lateral). A detailed description of the measurement capabilities and selected application of this measurement system are given by Kapłonek et al. [52]. The correlation between the geometrical parameter calculated from the image $A n$ and profile parameter $R a$ is presented in Figure 7. 


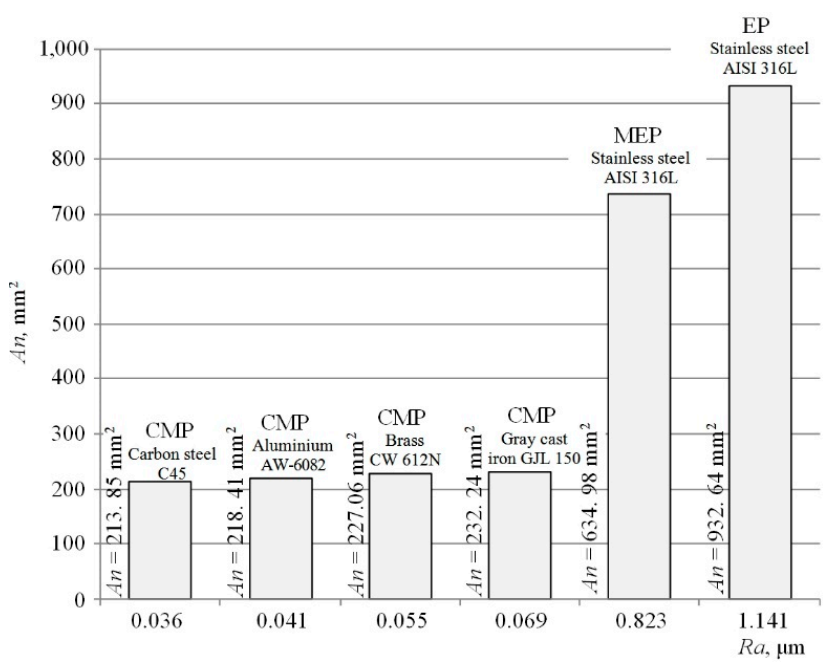

Figure 7. The set of average values of $A n$ area (of the bright regions of scattered light image) vs. $R a$ roughness average for surfaces after finishing by various variations of the polishing process.

The values presented in Figure 7 allow us to state that the MEP process is over $32 \%$ more effective than EP. The obtained surface has over $27 \%$ lower roughness and much better reflection properties, making it more advantageous. Comparison of surfaces after electrochemical polishing (EM, MEP) and conventional machine polishing (CMP) shows that CMP is over $68 \%$ more effective. The values of the $R a$ parameter decrease significantly, which indicates a relatively smooth surface with small heights of the surface irregularities (from $R a=0.036$ to $0.069 \mu \mathrm{m}$ ). High surface smoothing positively affects the reflection properties, which is important for these types of surfaces.

\section{Conclusions}

In the preliminary experimental studies presented in this article, the authors showed that one of the proposed light-scattering methods-angle-resolved scattering-can be successfully used for assessment of surfaces after electrochemical polishing in a magnetic field in relation to geo- and photometric parameters. Below, the most important conclusions resulting from the research are given.

1. The AISI 316L stainless austenitic steel samples divided into two groups (each 10 samples) were electrochemically polished in a magnetic field: MEP-800 (magnetic field: $66 \mathrm{mT}$, current density: $800 \mathrm{~A} / \mathrm{dm}^{2}$ ) and MEP-50 (magnetic field: $66 \mathrm{mT}$, current density: $500 \mathrm{~A} / \mathrm{dm}^{2}$ ) (Section 2.1). The samples after the process were characterized by relatively smooth surface with small heights of the surface irregularities. The average value of $R a$ roughness (profile) parameter measured by optical profilometer Talysurf CLI 2000 with laser triangulation sensor LK-031 for all magnetoelectropolished surfaces was $0.823 \mu \mathrm{m}$.

2. The obtained surface features were assessed by using one of the non-contact light-scattering methods for confirmation of correctness of carrying out the process. In this case, the angle-resolved scattering-based experimental setup was used. The surface of each sample was illuminated using a laser beam (wavelength $\lambda=635 \mathrm{~nm}$, angle of incidence $50^{\circ}$ ) and its angular distribution in the observation plane was acquired as a digital image (Section 2.2). After pre-processing (ImageJ 1.57) images, we carried out parametric analysis (Image Pro ${ }^{\circledR}$-Plus 5.1), which included the calculation of two key geo- and photometric parameters (Section 2.3).

3. The obtained values of area (of the bright regions of scattered light image) (Figure 5) and integrated optical density (of the bright regions of scattered light image) (Figure 6) were similar for the magnetoelectropolished surfaces of both types of samples. Additionally, we found that the above values (in each case) were approx. 50\% lower ( $A n_{\mathrm{MEP}}-49 \%$ (MEP-800) and over $49 \%$ (MEP-50); $I_{\Sigma \mathrm{MEP}}-51 \%$ (MEP-800) and 54\% (MEP-50), respectively) than those obtained for the 
base surface. This indicates a much smaller share of light scattering component at the gain of the specular reflection component. This is a very advantageous surface feature after the magnetoelectropolished process, especially useful in a wide range of industrial applications, in areas such as precision mechanical, chemical and biomedical engineering as well as optoand microelectronics.

4. Compared to electropolishing, the magnetoelectropolishing process is characterized by over $32 \%$ more effectiveness (Figure 7) at 27\% lower surface roughness $(R a)$. The results obtained for this type of surface (in the context of their reflection properties and surface texture properties) are very promising, which encourages further work to improve this electrochemical polishing process and study its effects.

Author Contributions: Supervision, W.K.; conceptualization, W.K., K.R., D.Y.P., research methodology, W.K., K.R., D.Y.P., investigation, W.K., K.R.; formal analysis, D.Y.P.; writing — original draft preparation, W.K.; writing一review and editing, K.R., D.Y.P. All authors have read and agreed to the published version of the manuscript.

Funding: This research received no external funding.

Conflicts of Interest: The authors declare no conflict of interest.

\section{Nomenclature}

\begin{tabular}{|c|c|}
\hline $\mathrm{AC}$ & Alternating current \\
\hline AFM & Atomic force microscopy \\
\hline ARS & Angle-resolved scattering \\
\hline BRDF & Bidirectional reflectance distribution function \\
\hline BSDF & Bidirectional scatter distribution function \\
\hline CCD & Charge-coupled device \\
\hline CLSM & Confocal laser scanning microscopy \\
\hline CMP & Conventional machine polishing \\
\hline DC & Direct current \\
\hline EP & Electropolishing \\
\hline FVM & Focus variation microscopy \\
\hline MEP & Magnetoelectropolishing \\
\hline MFM & Mirror facet model \\
\hline PSI & Phase shifting interferometry \\
\hline SIM & Surface imperfections \\
\hline SEM & Scanning electron microscopy \\
\hline T-S & Torrence-Sparrow theory \\
\hline$A$ & Illuminated surface area \\
\hline$A n$ & Area (of the bright regions of an image of scattered light) \\
\hline$d \Phi_{e}$ & Radiant flux/power scattered within the solid angle \\
\hline$d \Omega$ & Solid angle \\
\hline$A n$ & Area (of the bright regions of an image of scattered light) \\
\hline$f x$ & Spatial frequency ( $x$-axis) of the surface roughness \\
\hline fy & Spatial frequency ( $y$-axis) of the surface roughness \\
\hline$I_{(i, j)}$ & Grey scale intensity \\
\hline$I_{\Sigma}$ & Integrated optical density (of the bright regions of an image of scattered light) \\
\hline$i$ & Row number \\
\hline$j$ & Column number \\
\hline$L_{e}$ & Scatter surface radiance \\
\hline$Q$ & Non-dimensional factor depending on the azimuthal scattering angle $\phi$ \\
\hline$R a$ & Roughness average \\
\hline$S(f x, f y)$ & Two-dimensional surface power spectral density function \\
\hline$\theta_{i}$ & Angle of incidence \\
\hline$\theta_{d}$ & Scattering angle \\
\hline$\lambda$ & Wavelength of light \\
\hline$\Phi_{e i}$ & Radiant flux/power incident of surface \\
\hline
\end{tabular}




\section{References}

1. Practical guidelines for the fabrication of high performance austenitic stainless steels. Int. Molybdenum Assos. 2010, 1, 1-72.

2. Hryniewicz, T.; Rokosz, K. Polarization characteristics of magnetoelectropolishing stainless steels. Mater. Chem. Phys. 2010, 122, 169-174. [CrossRef]

3. Hryniewicz, T.; Rokosz, K. Investigation of selected surface properties of AISI 316L SS after magnetoelectropolishing. Mater. Chem. Phys. 2010, 123, 47-55. [CrossRef]

4. Lee, E.-S.; Park, J.-W.; Moon, Y.-H. Development of ultra clean machining technology with electrolytic polishing process. Int. J. Korean Soc. Precis. Eng. 2001, 2, 18-25.

5. Jacquet, P.A. Electrolytic method for obtaining bright copper surfaces. Nature 1935, 135, 1076. [CrossRef]

6. Elmore, W.C. Electrolytic polishing. J. Appl. Phys. 1939, 10, 724-727. [CrossRef]

7. Wagner, C. Contribution to the theory of electropolishing. J. Electrochem. Soc. 1954, 101, 225-228. [CrossRef]

8. Hoar, T.P.; Rothwell, G.P. The influence of solution flow on anodic polishing: Copper in aqueous o-phosphoric acid. Electrochim. Acta 1964, 9, 135-150. [CrossRef]

9. Hensel, K.B. Surface treatments-lectropolishing. Met. Finish. 1940, 38, 325-331.

10. Landolt, D. Fundamental aspects of electropolishing. Electrochim. Acta 1987, 32, 1-11. [CrossRef]

11. Kirchheim, R.; Maier, K.; Tölg, G. Diffusion and solid-film formation during electropolishing of metals. J. Electrochem. Soc. 1981, 128, 1027-1034. [CrossRef]

12. Grimm, R.D.; West, A.C.; Landolt, D. AC impedance study of anodically formed salt films on iron in chloride solution. J. Electrochem. Soc. 1992, 139, 1622-1629. [CrossRef]

13. Hryniewicz, T.; Rokicki, R.; Rokosz, K. Co-Cr alloy corrosion behaviour after electropolishing and magnetoelectropolishing treatments. Mater. Lett. 2008, 62, 3073-3076. [CrossRef]

14. Nawrat, G.; Marciniak, J.; Paszenda, Z.; Korczyński, A. Electrolytic surface processing of implants used in surgery. Pol. J. Appl. Chem. 1995, 39, 477-480.

15. Rokosz, K.; Hryniewicz, T.; Raaen, S. Cr/Fe ratio by XPS spectra of magnetoelectropolished AISI 316L SS fitted by Gaussian-Lorentzian shape lines. Teh. Vjesn. 2014, 21, 533-538.

16. Rokosz, K.; Hryniewicz, T. XPS measurements of LDX 2101 duplex steel surface after magnetoelectropolishing. Int. J. Mater. Res. 2013, 104, 1223-1232. [CrossRef]

17. Hryniewicz, T.; Konarski, P.; Rokosz, K.; Rokicki, R. SIMS analysis of hydrogen content in near surface layers of AISI 316L SS after electrolytic polishing under different conditions. Surf. Coat. Technol. 2011, 205, 4228-4236. [CrossRef]

18. Rokosz, K.; Hryniewicz, T.; Raaen, S.; Valicek, J. SEM/EDX, XPS, corrosion and surface roughness characterization of AISI 316L SS after electrochemical treatment in concentrated $\mathrm{HNO}_{3}$. Teh. Vjesn. 2015, 22, 125-131. [CrossRef]

19. Valicek, J.; Drzik, M.; Hryniewicz, T.; Harnicarova, M.; Rokosz, K.; Kusnerova, M.; Barcova, K.; Brazina, D. Non-contact method for surface roughness measurement after machining. Meas. Sci. Rev. 2012, 12, $184-188$. [CrossRef]

20. Rokosz, K.; Hryniewicz, T.; Raaen, S. Characterization of passive film formed on AISI 316L stainless steel after magnetoelectropolishing in a broad range of polarization parameters. Steel Res. Int. 2012, 83, 910-918. [CrossRef]

21. Hryniewicz, T.; Rokosz, K. Corrosion resistance of magnetoelectropolished AISI 316L SS biomaterial. Anti-Corros. Method Mater. 2014, 61, 57-64. [CrossRef]

22. Hryniewicz, T.; Rokosz, K.; Rokicki, R.; Prima, F. Nanoindentation and XPS studies of titanium TNZ alloy after electrochemical polishing in a magnetic field. Materials 2015, 8, 205-215. [CrossRef] [PubMed]

23. Rokosz, K.; Simon, F.; Hryniewicz, T.; Rzadkiewicz, S. Comparative XPS analysis of passive layers composition formed on AISI 304 L SS after standard and high-current density electropolishing. Surf. Interface Anal. 2015, 47, 87-92. [CrossRef]

24. Rokosz, K.; Lahtinen, J.; Hryniewicz, T.; Rzadkiewicz, S. XPS depth profiling analysis of passive surface layers formed on austenitic AISI 304L and AISI 316L SS after high-current-density electropolishing. Surf. Coat. Technol. 2015, 276, 516-520. [CrossRef]

25. Pahk, H.J.; Stout, K.; Blunt, L.A. Comparative study on the three-dimensional surface topography for the polished surface of femoral head. Int. J. Adv. Manuf. Technol. 2000, 16, 564-570. [CrossRef] 
26. Duparré, A.; Ferre-Borrull, J.; Gliech, S.; Notni, G.; Steinert, J.; Bennett, J.M. Surface characterization techniques for determining the root-mean-square roughness and power spectral densities of optical components. Appl. Opt. 2002, 41, 154-171. [CrossRef] [PubMed]

27. Rebeggiani, S.; Rosén, B.-G. Quantitative evaluation of the surface finish of high gloss polished tool steels. Surf. Topog-Metrol. 2013, 2, 014002. [CrossRef]

28. Calaon, M.; Madsen, M.H.; Weirich, J.; Hansen, H.N.; Tosello, G.; Hansen, P.E.; Garnaes, J.; Tang, P.T. Replication fidelity assessment of large area sub- $\mu \mathrm{m}$ structured polymer surfaces using scattero-metry. Surf. Topog-Metrol. 2015, 3, 045005. [CrossRef]

29. Azarova, V.V.; Dmitriev, V.G.; Lokhov, Y.N.; Malitskii, K.N. Measuring the roughness of high-precision quartz substrates and laser mirrors by angle-resolved scattering. J. Opt. Technol. 2002, 69, 125. [CrossRef]

30. Bloomstein, T.M.; Hardy, D.E.; Gomez, L.; Rothschild, M. Angle-resolved scattering measurements of polished surfaces and optical coatings at $157 \mathrm{~nm}$. Proc. SPIE 2003, 5040, 742-752.

31. Schröder, S.; Herffurth, T.; Trost, M.; Duparré, A. Angle-resolved scattering and reflectance of extreme-ultraviolet multilayer coatings: Measurement and analysis. Appl. Opt. 2010, 49, 1503-1512. [CrossRef] [PubMed]

32. Zhenrong, Z.; Jing, Z.; Peifu, G. Roughness characterization of well-polished surfaces by measurements of light scattering distribution. Opt. Appl. 2010, 40, 811-818.

33. Kapłonek, W.; Nadolny, K. Laser methods based on an analysis of scattered light for automated, in-process of light scattering distribution. Opt. Appl. 2015, 126, 2764-2770. [CrossRef]

34. Torrance, K.E.; Sparrow, E.M. Theory for off-specular reflection from roughened surfaces. J. Opt. Soc. Am. 1967, 57, 1105-1114. [CrossRef]

35. Łukianowicz, C. Use of light scattering method to assess the texture of electropolished surfaces. In International Conference on Innovations Induced by Research in Technical Systems; Majewski, M., Kacalak, W., Eds.; Springer Nature: Cham, Switzerland, 2020; pp. 148-157.

36. Nicodemus, F.E. Reflectance nomenclature and directional reflectance and emissivity. Appl. Opt. 1970, 9, 1474-1475. [CrossRef]

37. Shen, Y.-F.; Lim, H.-S.; Kim, H.-Y.; Ahn, J.-H. A study on roughness measurement of polished surfaces using reflected laser beam image. J. Korean Soc. Precis. Eng. 1999, 16, 145-152.

38. Espinosa-Luna, R.; Atondo-Rubio, G.; Hinojosa-Ruiz, S. Enhancement backscattering of light: A direct visual-desktop experience. Rev. Mex. Fís. 2011, 57, 524-527.

39. Kapłonek, W.; Łukianowicz, C.; Nadolny, K. Methodology of the assessment of the abrasive tool's active surface using laser scatterometry. Trans. Can. Soc. Mech. Eng. 2012, 36, 49-66. [CrossRef]

40. Jošt, M.; Krč, J.; Topič, M. Camera-based angular resolved spectroscopy system for spatial measurements of scattered light. Appl. Opt. 2014, 53, 4795-4803. [CrossRef]

41. Kapłonek, W.; Nadolny, K. Laser method based on imaging and analysis of scattered light used for assessment of cylindrical surfaces after dynamic burnishing process. Int. J. Surf. Sci. Eng. 2016, 10, 55-72. [CrossRef]

42. Rao, C.B.; Raj, B. Study of engineering surfaces using laser-scattering techniques. Sadhana 2003, $28,739-761$. [CrossRef]

43. Kapłonek, W.; Nadolny, K.; Wojtewicz, M.; Sienicki, W. Characterisation of abrasive tools active surface after the impregnation process by modified ARS method based on imaging and analysis of the scattered light. Int. J. Mach. Mach. Mater. 2015, 17, 397-417. [CrossRef]

44. Kapłonek, W.; Łukianowicz, C. Assessment of surface microroughness in movement by laser scatterometry and image stacking. Prze. Elektrotech. 2008, 84, 155-160.

45. Abràmoff, M.D.; Magalhães, P.J.; Ram, S.J. Image processing with Image. J. Biophotonics Int. 2004, 11, 36-42.

46. Schneider, C.A.; Rasband, W.S.; Eliceiri, K.W. NIH Image to ImageJ: 25 years of image analysis. Nat. Methods 2012, 9, 671-675. [CrossRef] [PubMed]

47. Rueden, C.T.; Schindelin, J.; Hiner, M.C.; DeZonia, B.E.; Walter, A.E.; Arena, E.T.; Eliceiri, K.W. ImageJ2: ImageJ for the next generation of scientific image data. BMC Bioinform. 2017, 1, 529-554. [CrossRef]

48. Fritzsch, R.; Mirzaei, B.; Kennedy, M.W.; Aune, R.E. Automated quantification of SiC-particles in solidified A356 aluminium using Image-Pro ${ }^{\circledR}$ Plus 7.0. In Characterization of Minerals, Metals, and Materials 2013; Hwang, J.-Y., Bai, C., Carpenter, J.S., Ikhmayies, S., Li, B., Monteiro, S.N., Peng, Z., Zhang, M., Eds.; Wiley: Hoboken, NJ, USA, 2013; pp. 67-77. 
49. Dongming, W. Application of Image-Pro Plus in quantitative study on volume fraction of composite. Foundry Technol. 2012, 33, 1273-1275.

50. Ye, H.; Jianhong, A.N.; Sisi, Z.; Hong, S. Image-Pro Plus and ImageJ: Comparison and application in image analysis of biological tissues. Chin. J. Stereol. Image Anal. 2015, 20, 185-196.

51. Geometrical Product Specification (GPS). Surface Imperfections. Terms, Definitions and Parameters; European Committee for Standardization: Bruxelles, Belgium, 1999; EN-ISO 8785:1999.

52. Kapłonek, W.; Sutowska, M.; Ungureanu, M.; Çetinkaya, K. Optical profilometer with confocal chromatic sensor for high-accuracy 3D measurements of the uncirculated and circulated coins. J. Mech. Energy Eng. 2018, 2, 181-192. [CrossRef]

(C) 2020 by the authors. Licensee MDPI, Basel, Switzerland. This article is an open access article distributed under the terms and conditions of the Creative Commons Attribution (CC BY) license (http://creativecommons.org/licenses/by/4.0/). 